\title{
Revisiting the ENSO Teleconnection to the Tropical North Atlantic
}

\author{
JAVIER GARCÍA-SERRANO \\ ๖ \\ Barcelona Supercomputing Center, Barcelona, Spain \\ CHRISTOPHE CASSOU \\ CERFACS/CNRS, Toulouse, France \\ Hervé DOUVILle \\ CNRM-GMGEC, Météo-France, Toulouse, France \\ ALESSANDRA GIANNINI \\ International Research Institute for Climate and Society, Columbia University, Palisades, New York \\ FRANCISCO J. DOBLAS-REYES \\ Barcelona Supercomputing Center, and Institució Catalana de Recerca i Estudis Avançats, Barcelona, Spain
}

(Manuscript received 29 August 2016, in final form 21 May 2017)

\begin{abstract}
One of the most robust remote impacts of El Niño-Southern Oscillation (ENSO) is the teleconnection to tropical North Atlantic (TNA) sea surface temperature (SST) in boreal spring. However, important questions still remain open. In particular, the timing of the ENSO-TNA relationship lacks understanding. The three previously proposed mechanisms rely on teleconnection dynamics involving a time lag of one season with respect to the ENSO mature phase in winter, but recent results have shown that the persistence of ENSO into spring is necessary for the development of the TNA SST anomalies. Likewise, the identification of the effective atmospheric forcing in the deep TNA to drive the regional air-sea interaction is also lacking. In this manuscript a new dynamical framework to understand the ENSO-TNA teleconnection is proposed, in which a continuous atmospheric forcing is present throughout the ENSO decaying phase. Observational datasets in the satellite era, which include reliable estimates over the ocean, are used to illustrate the mechanism at play. The dynamics rely on the remote Gill-type response to the ENSO zonally compensated heat source over the Amazon basin, associated with perturbations in the Walker circulation. For El Niño conditions, the anomalous diabatic heating in the tropical Pacific is compensated by anomalous diabatic cooling, in association with negative rainfall anomalies and descending motion over northern South America. A pair of anomalous cyclonic circulations is established at upper-tropospheric levels in the tropical Atlantic straddling the equator, displaying a characteristic baroclinic structure with height. In the TNA region, the mirrored anomalous anticyclonic circulation at lower-tropospheric levels weakens the northeasterly trade winds, leading to a reduction in evaporation and of the ocean mixed layer depth, hence to positive SST anomalies. Apart from the dominance of latent heat flux anomalies in the remote response, sensible heat flux and shortwave radiation anomalies also appear to contribute. The "lagged" relationship between mature ENSO in winter and peaking TNA SSTs in spring seems to be phase locked with the seasonal cycle in both the location of the mechanism's centers of action and regional SST variance.
\end{abstract}

(c) Copyright [2017] American Meteorological Society (AMS). Permission to use figures, tables, and brief excerpts from this work in scientific and educational works is hereby granted provided that the source is acknowledged. Any use of material in this work that is determined to be "fair use" under Section 107 of the U.S. Copyright Act or that satisfies the conditions specified in Section 108 of the U.S. Copyright Act (17 USC \$108) does not require the AMS’s permission. Republication, systematic reproduction, posting in electronic form, such as on a website or in a searchable database, or other uses of this material, except as exempted by the above statement, requires written permission or a license from the AMS. All AMS journals and monograph publications are registered with the Copyright Clearance Center (http:// www.copyright.com). Questions about permission to use materials for which AMS holds the copyright can also be directed to the AMS Permissions Officer at permissions@ametsoc.org. Additional details are provided in the AMS Copyright Policy statement, available on the AMS website (http://www.ametsoc.org/CopyrightInformation).

\footnotetext{
Denotes content that is immediately available upon publication as open access.
}

Supplemental information related to this paper is available at the Journals Online website: http://dx.doi.org/10.1175/ JCLI-D-16-0641.s1.

Corresponding author: Javier García-Serrano, javier.garcia@bsc.es 


\section{Introduction}

El Niño-Southern Oscillation (ENSO) is the first mode of global climate variability on seasonal-tointerannual time scales (e.g., Deser et al. 2010). One of the main reasons for the attention ENSO receives is that it affects weather/climate variability over large parts of the world. Such remote effects are called ENSO teleconnections. This study focuses on the canonical or eastern Pacific ENSO phenomenon (Capotondi et al. 2015), characterized by sea surface temperature (SST) anomalies with an arrowhead shape off the South American coastline, for which robust atmospheric teleconnections have been established (e.g., Trenberth et al. 1998; Alexander et al. 2002). A convenient measure of ENSO is the Niño-3.4 index, defined as the anomaly of SST averaged over the region $5^{\circ} \mathrm{S}-5^{\circ} \mathrm{N}, 170^{\circ}-120^{\circ} \mathrm{W}$; the strength of an ENSO teleconnection is defined as the linear regression coefficient of the field in question on Niño-3.4 (e.g., Sterl et al. 2007; Yang and DelSole 2012). One of the most robust ENSO teleconnections is the link between SST anomalies in the equatorial Pacific and those in the tropical North Atlantic (TNA): a broad region of positive (negative) SST anomalies to the north of the equatorial Atlantic lags the mature phase of El Niño (La Niña) in boreal winter [December-February (DJF)], peaking in boreal spring [March-May (MAM)] (e.g., Lee et al. 2008). This one-season-lagged ENSOTNA teleconnection is linear with respect to the phase of ENSO (e.g., Czaja et al. 2002; Handoh et al. 2006).

Three mechanisms have been proposed so far to explain the ENSO-TNA teleconnection, which are schematically summarized in Fig. 1 (left). A number of works have shown that latent heat flux changes associated with variations in the trade wind intensity during winterspring are of primary importance for the ENSO-related SST anomaly in the TNA region, which is thought to be ultimately mediated by the wind-evaporation-SST (WES) feedback (Enfield and Mayer 1997; Klein et al. 1999; Giannini et al. 2000, 2001). While the precise origin of these trade wind anomalies remains unclear, two teleconnection mechanisms have addressed their genesis. The first one consists of changes induced by the tail of the Rossby wave train forced from the tropical Pacific and crossing the North Pacific-American sector (Enfield and Mayer 1997; Giannini et al. 2000; blue diagram in Fig. 1, left). The second one involves a more direct atmospheric bridge, resulting in changes of the Atlantic meridional (Hadley) circulation as a consequence of perturbations over the equatorial Atlantic convective region in response to changes of the Pacific zonal (Walker) circulation (Klein et al. 1999; Wang 2005; black diagram in Fig. 1, left). Both teleconnection mechanisms act upon the strength of the Azores anticyclone (and related trade winds), which represents an atmospheric forcing of the subtropical circulation that does not appear to trigger the WES feedback (Handoh et al. 2006), since the latter is mainly confined to the deep tropics $\left(0^{\circ}-10^{\circ} / 15^{\circ} \mathrm{N}\right.$; Czaja et al. 2002). Modeling (Chang et al. 2001) and observational (Chiang et al. 2002) studies have found that positive feedback between cross-equatorial winds and SST gradient takes place only in the deep TNA. Hence, it seems that a tropical atmospheric forcing is missing in the understanding of the ENSO influence on TNA SSTs.

Another puzzling characteristic in the ENSO-TNA teleconnection concerns its "lagged" relationship. All the previous works involving the two mechanisms above suggest that the ENSO impact on the TNA SST variability simply results from a modulation of the strength of the trade winds in winter, when the extratropical ENSO influence is most prominent. However, a recent study has shown that the duration of the ENSO events is crucial for its springtime teleconnection to the tropical North Atlantic. Lee et al. (2008) have shown that only those ENSO events persisting into spring are able to force a significant SST anomaly over the TNA region during its decay. They even showed that if ENSO is abruptly terminated in March, the intertropical connection is largely reduced (more than half) and TNA SST may remain neutral in late spring. The third teleconnection mechanism proposed so far to explain the ENSO-TNA relationship also fails in this regard, as it invokes a one-season lag relative to the peak of ENSO as well (Yulaeva and Wallace 1994). This is the tropospheric temperature mechanism (Chiang and Sobel 2002; Chiang and Lintner 2005; Chang et al. 2006), a tropics-wide mechanism in which upper-tropospheric temperature anomalies are linked to the surface via moist convection/stability processes. The structure of the anomalous temperature signal in the upper troposphere is consistent with the eastward propagation of a Kelvin wave front triggered from the ENSO heating anomaly in the tropical Pacific (e.g., Lin et al. 2007; Lintner and Chiang 2007; red diagram in Fig. 1, left). Besides, its relevance to the TNA region still needs to be quantified, since this ENSO-related dynamical response has the strongest effect near the equator (Chiang and Sobel 2002).

All these differing lines of evidence suggest that the ENSO-TNA relationship needs to be revisited. A fourth teleconnection mechanism is identified in this manuscript (green diagram in Fig. 1, right). Taking into account the important role of the Pacific SST evolution on the ENSO-TNA relationship, one would expect a direct, no-lagged mechanism that communicates quickly 
ENSO-TNA teleconnection (EI Niño)
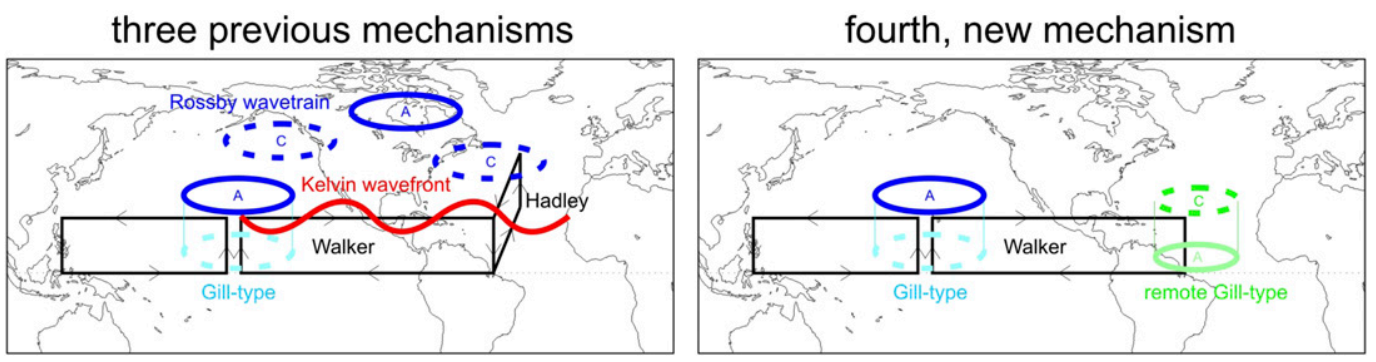

FIG. 1. Schematic diagram of the different mechanisms proposed to explain the ENSO-TNA teleconnection. (left) Previous mechanisms via an extratropical Rossby wave train (rotational circulation; blue); through an atmospheric bridge involving changes in the Pacific Walker and Atlantic Hadley cells (divergent circulation; black); and via the tropospheric temperature mechanism, which is mediated by the propagation of a Kelvin wave front (equatorial dynamics; red). (right) New mechanism via the remote Gill-type response to the ENSO zonally compensated heat source over the Amazon basin, associated with changes in the Pacific Walker cell (tropical dynamics; green). Note that in the Gill-type responses, over both the tropical Pacific and Atlantic, only the anomalous circulations in the Northern Hemisphere are drawn. Thin arrows indicate the direction of the divergent cells. Solid (dashed) circles represent anticyclonic $A$ (cyclonic $C$ ) circulations associated with high (low) pressure systems.

the remote forcing to the TNA during the ENSO decay. This hypothesis points at purely tropical dynamics as the main candidate, since the tropical atmosphere responds almost simultaneously to the establishment of anomalous SSTs (e.g., Giannini et al. 2001). Previous works have shown that the diabatic heat source during ENSO events perturbs the zonal Walker circulation in such a way that associated branches yield anomalous diabatic heat sources (opposite in sign to the ENSO anomaly) on both sides of the tropical Pacific, that is, over the Maritime Continent and South America (Nigam et al. 2000; DeWeaver and Nigam 2002). These zonally compensated heat sources lead to secondary Gill-type responses over those remote tropical basins, inducing twin anomalous circulation centers straddling the equator (DeWeaver and Nigam 2004; Spencer et al. 2004; Sasaki et al. 2015). This fast, linear mechanism could be acting in the ENSO-TNA teleconnection. Note that a similar working hypothesis has been proposed to explain the influence of ENSO (Jang and Straus 2013) and the Atlantic Niño (Kucharski et al. 2007, 2008, 2009) on the Indian summer monsoon. While the atmospheric bridge mechanism (involving changes of the Atlantic Hadley circulation) and this fourth mechanism (with the remote Gill-type response) both rely on perturbations of the Pacific Walker circulation and may appear not to be distinct from each other, there is a subtle difference in the teleconnections: the dynamics of the former are of divergent origin, and those of the latter are of rotational (nondivergent) origin (e.g., Wang 2005; Lee et al. 2009).

The objective of this study is to illustrate that a secondary Gill-type structure in the tropical Atlantic is potentially at work in the ENSO-TNA teleconnection.
A companion study (J. García-Serrano et al. 2017, unpublished manuscript) will address the actual predictability of TNA SSTs in seasonal forecast systems and the contribution of ENSO to the prediction skill.

\section{Datasets and methodology}

The target period for the winter (DJF) Niño-3.4 index is 1982/83-2010/11, which overlaps the effective hindcast period in most of the current forecast systems (e.g., Kirtman et al. 2014; Stockdale et al. 2015). Note that this period is representative of the robust and stationary ENSO-TNA relationship (Fig. S1 in the supplemental material). SST data from Extended Reconstructed SST, version 3b (ERSST.v3b; Smith et al. 2008), and Hadley Centre Sea Ice and Sea Surface Temperature, version 1.1 (HadISST.v1.1; Rayner et al. 2003), are used. The SST results shown in the manuscript are mainly from ERSST.v3b; nevertheless, both datasets provide almost identical results (e.g., Fig. 2a for the DJF Niño-3.4 index; Fig. 9, described in greater detail below, for the autocorrelation of the TNA SST index).

A linear approach is adopted to characterize the evolution of a canonical ENSO event (either El Niño or La Niña) and for ease of comparison with previous works (e.g., Sutton et al. 2000). Regression maps of different fields onto the DJF Niño-3.4 index are performed. Variables employed include surface wind at $10 \mathrm{~m}$, streamfunction and velocity potential at 850 and $200 \mathrm{hPa}, 12-24-\mathrm{h}$ forecast-accumulated latent and sensible heat flux, and downward shortwave and upward longwave radiation at surface from ERAInterim (Dee et al. 2011); precipitation from NASA 


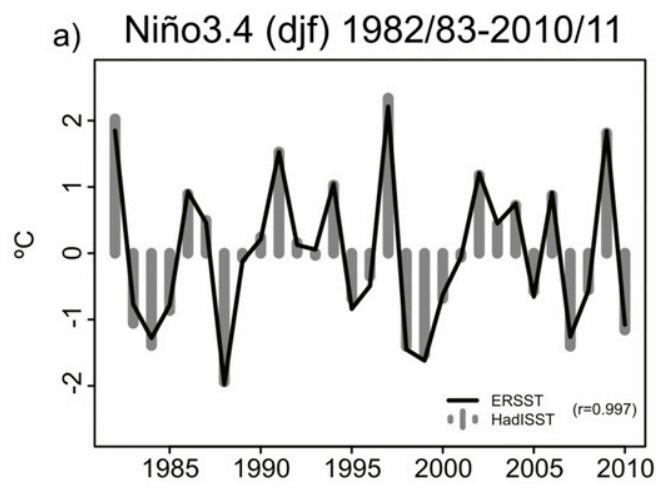

Niño3.4 (djf) x SST/wind-10m (djf) Niño3.4 (djf) x GPCP/divergent-200 (djf)
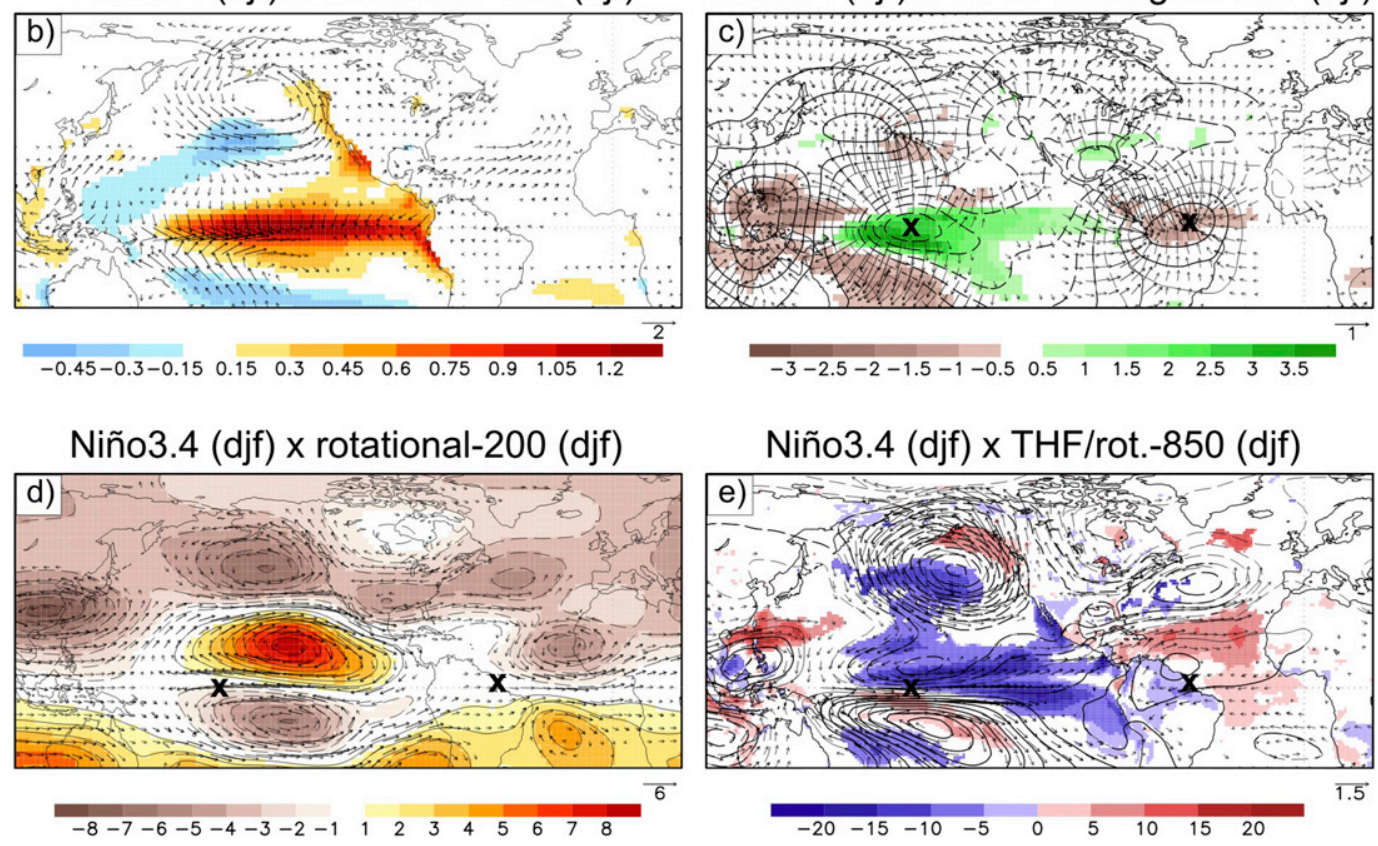

FIG. 2. (a) Niño-3.4 SST index in DJF from ERSST.v3b (black lines) and HadISST.v1.1 (gray bars). Regression

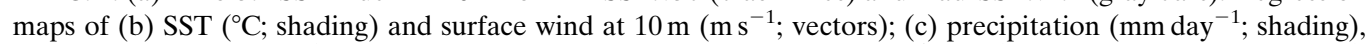
velocity potential $\left[\mathrm{m}^{2} \mathrm{~s}^{-1}\right.$; contours with contour interval $\left.(\mathrm{ci})=0.3 \times 10^{6} \mathrm{~m}^{2} \mathrm{~s}^{-1}\right]$, and divergent wind $\left(\mathrm{m} \mathrm{s}^{-1}\right.$; vectors) at $200 \mathrm{hPa}$; (d) streamfunction $\left(\mathrm{m}^{2} \mathrm{~s}^{-1}\right.$; contours with ci $\left.=1 \times 10^{6} \mathrm{~m}^{2} \mathrm{~s}^{-1}\right)$ and rotational wind $\left(\mathrm{m} \mathrm{s}^{-1}\right.$; vectors) at $200 \mathrm{hPa}$; and (e) THF ( $\mathrm{W} \mathrm{m}^{-2}$; shading; latent plus sensible where downward is positive), streamfunction $\left(\mathrm{m}^{2} \mathrm{~s}^{-1}\right.$; contours with ci $\left.=0.3 \times 10^{6} \mathrm{~m}^{2} \mathrm{~s}^{-1}\right)$, and rotational wind $\left(\mathrm{m} \mathrm{s}^{-1}\right.$; vectors $)$ at $850 \mathrm{hPa}$ anomalies in DJF onto the DJF Niño-3.4 index. Statistically significant areas at $95 \%$ confidence level are gridded for shading and vectors in (b), (c), and (e) and bolded/shaded for contours in (c)-(e). Thick, black crosses in (c)-(e) stand for the region of max divergence/convergence in the tropical Pacific/Amazon basin.

land-ocean Global Precipitation Climatology Project, version 2.2 (Adler et al. 2003); and mixed layer depth from ECMWF-Ocean Reanalysis System 4 (ORAS4; Balmaseda et al. 2013). Note that the analysis of atmospheric fields using NCEP-NCAR reanalyses (Kalnay et al. 1996) in the target period 1982/83-2010/11 (Fig. S2) or over the extended period 1948/49-2014/15 (Fig. S3) provide similar results. Seasonal means are constructed and the annual cycle is removed. To reduce the effect of long-term trends, a first-order polynomial (i.e., linear trend) is removed from all anomalies. It was verified that the results were not sensitive to this particular criteria. Statistically significant areas are assessed with the twotailed Student's $t$ test at 95\% confidence level.

\section{Results}

Figure 2 shows contemporaneous regression maps onto the Niño-3.4 index in DJF (Fig. 2a, black line), which depict well-known features of El Niño's mature 
phase. The SST map shows a prominent anomalous warm tongue over the central-eastern tropical Pacific surrounded by cold SST anomalies (Fig. 2b). This anomalous thermal forcing at surface translates into atmospheric forcing linked to changes in deep convection, leading to positive rainfall anomalies in the central tropical Pacific (Fig. 2c). The associated anomalous upper-tropospheric divergence (Fig. 2c) reinforces the local Hadley circulation converging at midlatitudes (e.g., Wang 2005) and triggers an extratropical wave train crossing the North Pacific-American sector (Fig. 2d) that has a strong barotropic structure with height (Fig. 2e). The latter is consistent with linear, stationary Rossby wave propagation (Hoskins and Karoly 1981; Sardeshmukh and Hoskins 1988). Also associated with the anomalous diabatic heating in the central Pacific are twin upper-level anticyclonic anomalies straddling the equator (Fig. 2d), which show a baroclinic structure (Fig. 2e). This is consistent with the tropical Gill-Matsuno solution (hereafter, Gill-type response for brevity; Matsuno 1966; Gill 1980). Note that deviations from the idealized Gill-type solution, with the lower (upper)-level Rossby gyres located directly to the north and south (to the east/downstream) of the maximum divergence, instead of to the west/upstream, are due to the background flow in observations (Lee et al. 2009).

The anomalous Walker circulation related to El Niño in DJF yields anomalous upper-tropospheric convergence and negative rainfall anomalies on both sides of the tropical Pacific, namely, over the Maritime Continent and South America (Fig. 2c). These remote perturbations are associated with the zonal compensation of the anomalous heat source (diabatic heating), representing two anomalous heat sinks (diabatic cooling; e.g., Lau and Chan 1983; Nigam et al. 2000). This aspect of the tropical ENSO teleconnections is largely linear (DeWeaver and Nigam 2002). The secondary forcings, opposite in sign to the one in the central Pacific, generate regional Gill-type responses of opposite polarity (DeWeaver and Nigam 2004; Spencer et al. 2004) with a pair of anomalous upper-level cyclonic circulations straddling the equator in the Indo-Pacific and tropical Atlantic regions (Fig. 2d), which also have a baroclinic structure with height (Fig. 2e). As in the tropical Pacific, deviations from the idealized Gill-type solution in the tropical Atlantic are due to the background flow (Lee et al. 2009), which are also observed in MAM (Sasaki et al. 2015). The focus of this study is the evolution of the secondary Gill-type response in the tropical Atlantic and its link to TNA SST anomalies.

ENSO is related to weak and nonstatistically significant positive TNA SST anomalies in DJF (Fig. 2b; see also Fig. S4). In contrast, one season later during its decaying phase (MAM), ENSO reaches its maximum impact on TNA SSTs (Fig. 3e). The amplitude of the peaking SST anomalies is around $0.3^{\circ} \mathrm{C}$, which is in agreement with previous works (e.g., Saravanan and Chang 2000). Figure 3 shows the progressive development of the remote SST anomaly from late winter [January-March (JFM); Fig. 3a], through early spring [February-April (FMA); Fig. 3c], to MAM (Fig. 3e). As introduced in section 1, it has long been argued that the ENSO-TNA teleconnection is mediated by changes in the Atlantic trade winds induced during winter. However, Lee et al. (2008) questioned this assumption and found that a continuous forcing of ENSO is needed to establish the intertropical connection. Here it is demonstrated that a continuous atmospheric forcing is at play. The regression sequence of surface wind reveals a striking difference between winter and spring: in DJF (Fig. 2b), the weakened trades mainly spread over the subtropical North Atlantic, approximately north of $15^{\circ} \mathrm{N}$, whereas in MAM (Fig. 3e), the weakened trades are confined to the deep TNA, mostly $0^{\circ}-15^{\circ} \mathrm{N}$. JFM (Fig. 3a) and FMA (Fig. 3c) display the transition from one to the other. These results are fully consistent with the composite analysis of Chiang et al. (2002, their Fig. 8). Accompanying the ENSO modulation of the wind strength there is concomitant, diminished ocean heat loss through turbulent heat flux (THF; i.e., downward anomalies) linked to reduced evaporation (Figs. 2e and $4 b, d, f)$.

Variations in the mixed layer depth (MLD) modify the heat capacity of the mixed layer, thus affecting the development of SST anomalies. Weakened trades lead to less mixing and downward heat fluxes (positive to the ocean), which increase stratification, stabilizing the mixed layer. A reduction of the MLD is associated with positive SST anomalies (e.g., Deser et al. 2010). The regression sequence of MLD follows the transition of the trade wind anomalies described above, from a tilted band in the subtropical North Atlantic (Figs. 5a,b) to the confinement into the deep, central TNA region (Figs. 5c,d). A close inspection suggests that the former is driven by the strength of the subtropical forcing whereas the latter is controlled by the location of the tropical forcing, with no apparent link between the two (Fig. 5e). Note that the central TNA region is the only area where the MLD becomes deeper in MAM (Fig. 6c), and it also shows an increase in variance (see Fig. 8a, described in greater detail below).

The remote TNA teleconnection sets up during the ENSO decaying phase. Note that the weakening of its SST signature in the tropical Pacific projects on the seasonal decrease in SST variance (cf. Figs. 2b, 3e with 
Niño3.4 (djf) x SST/wind-10m (jfm)

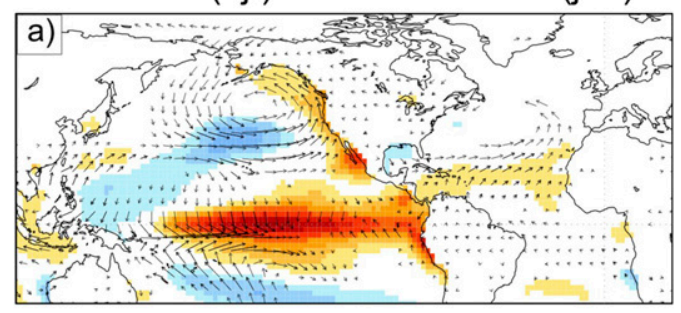

Niño3.4 (djf) x SST/wind-10m (fma)

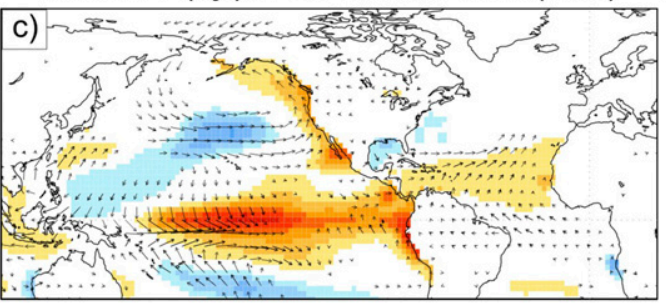

Niño3.4 (djf) x GPCP/divergent-200 (jfm)

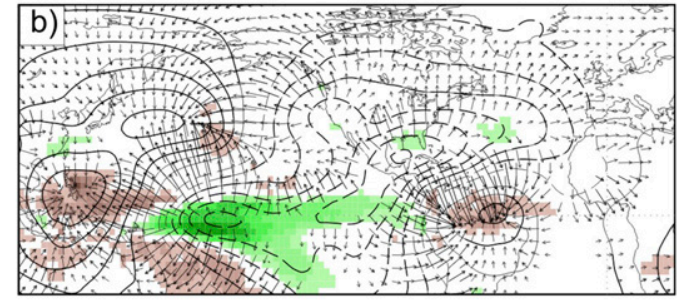

Niño3.4 (djf) x GPCP/divergent-200 (fma)

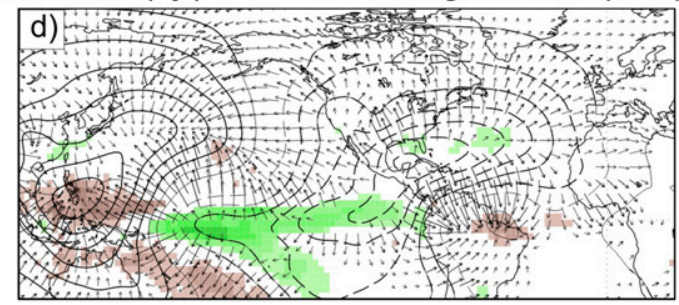

Niño3.4 (djf) x SST/wind-10m (mam) Niño3.4 (djf) x GPCP/divergent-200 (mam)
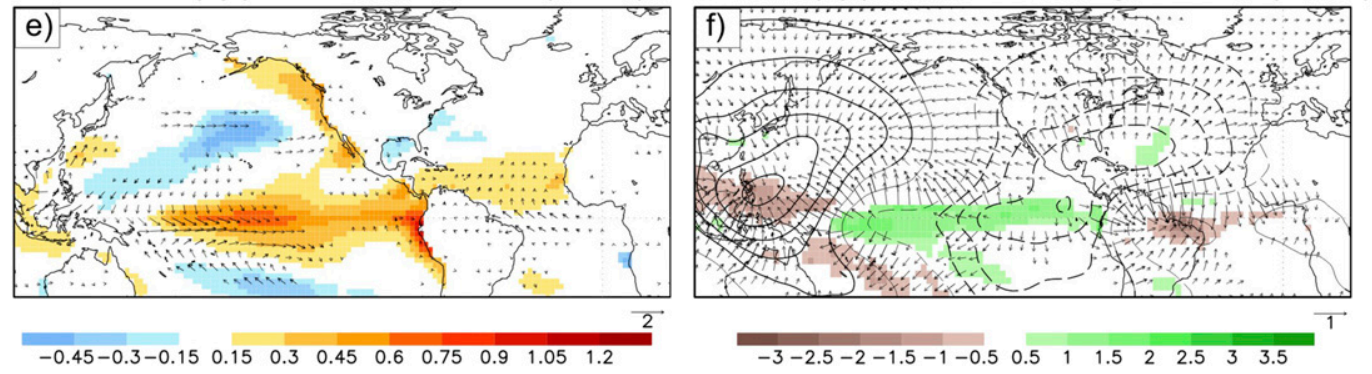

FIG. 3. Regression maps of (left) SST $\left({ }^{\circ} \mathrm{C}\right.$; shading) and surface wind at $10 \mathrm{~m}\left(\mathrm{~m} \mathrm{~s}^{-1}\right.$; vectors) and (right) precipitation ( $\mathrm{mm} \mathrm{day}^{-1}$; shading), velocity potential $\left(\mathrm{m}^{2} \mathrm{~s}^{-1}\right.$; contours with $\left.\mathrm{ci}=0.3 \times 10^{6} \mathrm{~m}^{2} \mathrm{~s}^{-1}\right)$, and divergent wind $\left(\mathrm{m} \mathrm{s}^{-1}\right.$; vectors) at $200 \mathrm{hPa}$ anomalies in (top) JFM, (middle) FMA, and (bottom) MAM onto the DJF Niño-3.4 index. Statistically significant areas at $95 \%$ confidence level are gridded for shading and vectors, and bolded for contours.

Figs. 6a,b). Still, the persistence of the thermal forcing associated with ENSO maintains the perturbation in the Walker circulation and yields consistent rainfall anomalies in the tropical band, albeit weakened, during the winter-to-spring evolution (Figs. 3b,d,f). The continuous ENSO zonally compensated diabatic heating, that is, heat sink, over the Amazon basin generates a continuous, baroclinic Gill-type response (Fig. 4). In particular for MAM, the lower-tropospheric anticyclonic anomaly represents an atmospheric forcing of the surface circulation, driving anomalous easterly winds at equatorial latitudes and anomalous southwesterly winds to the north (Fig. 4f); note that its extent is reduced as compared to DJF (Fig. 2e) and embedded in the TNA region. The ENSO-related weakening of the Atlantic trades in MAM (Fig. 3e) follows this anomalous anticyclonic circulation over the central TNA, with little contribution from the subtropics unlike in DJF (Figs. $2 \mathrm{~b}, \mathrm{e})$. This area shows maximum reduction in MLD
(Fig. 5d) and, consistent with the weakened trade winds, it also shows large downward latent heat flux anomalies linked to reduced evaporation (Fig. 7a). Sensible heat flux anomalies appear also to contribute to the TNA oceanic response, but weakly (Fig. 7b; Chiang and Lintner 2005). Another important element in the heat budget over the central TNA is the anomalous downward shortwave radiation (Fig. 7c; Alexander and Scott 2002), likely driven by the relative descending motion/ clear-sky conditions associated with the baroclinic structure (Figs. 4e,f), whereas the anomalous longwave radiation tends to oppose (Fig. 7d).

A conceptual model for the ENSO-induced TNA SST anomaly based on the total heat flux at surface (Fs; albeit dominated by latent heat flux anomalies) can be formulated as follows (e.g., Czaja et al. 2002): $\Delta \mathrm{SST} / \Delta t=$ $\mathrm{Fs} /\left(\rho C_{p} \mathrm{MLD}\right)$, where $t$ is time, $\rho=10^{3} \mathrm{~kg} \mathrm{~m}^{-3}$ is the density of water and $C_{p}=4000 \mathrm{~J} \mathrm{~kg}^{-1} \mathrm{~K}^{-1}$ is its heat capacity. For a climatological MLD value of $40 \mathrm{~m}$ in MAM and 

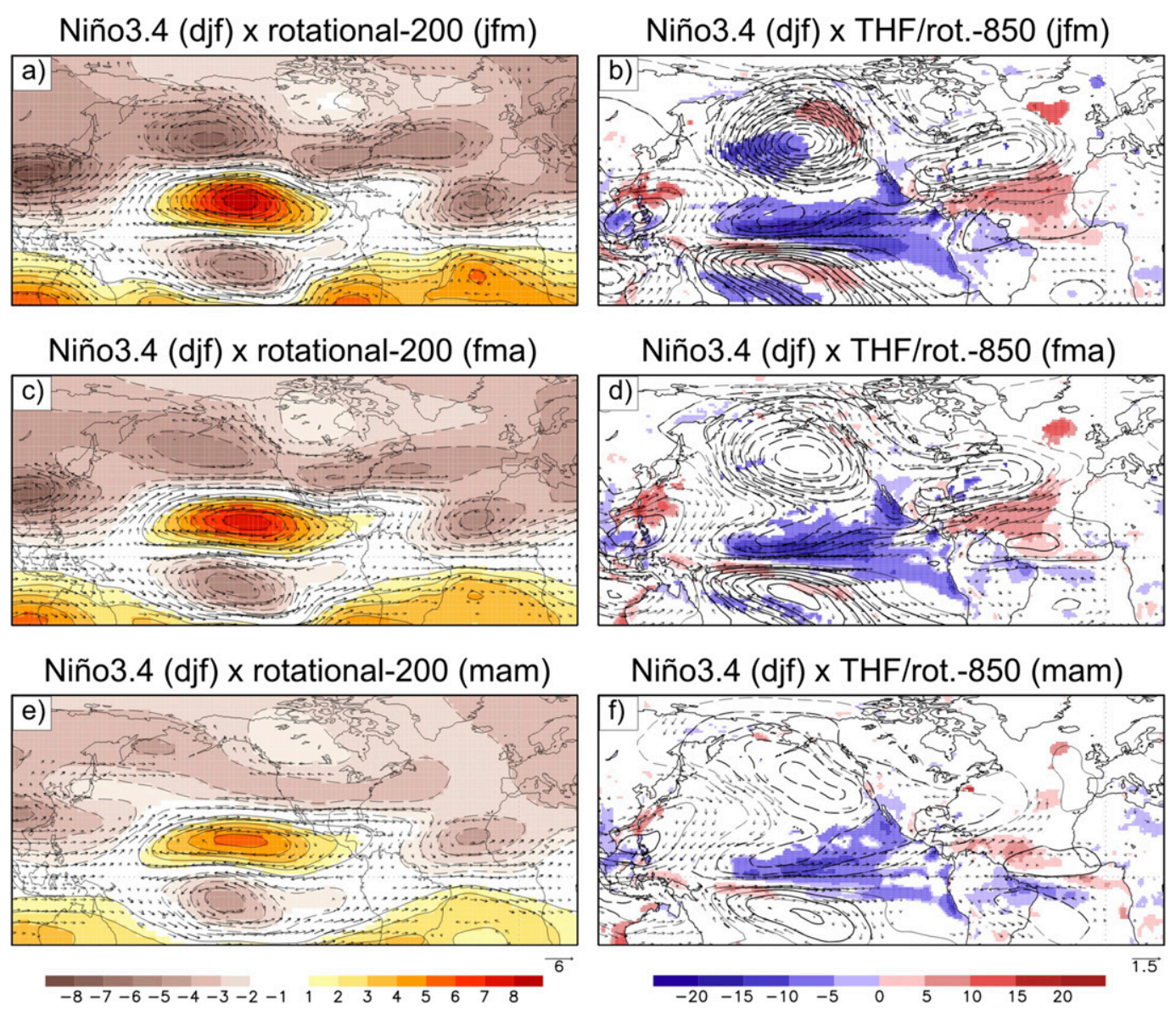

FIG. 4. Regression maps of (left) streamfunction $\left(\mathrm{m}^{2} \mathrm{~s}^{-1}\right.$; contours with ci $\left.=1 \times 10^{6} \mathrm{~m}^{2} \mathrm{~s}^{-1}\right)$ and rotational wind $\left(\mathrm{m} \mathrm{s}^{-1}\right.$; vectors) at $200 \mathrm{hPa}$ anomalies and (right) THF $\left(\mathrm{W} \mathrm{m}^{-2}\right.$; shading; latent plus sensible where downward is positive), streamfunction $\left(\mathrm{m}^{2} \mathrm{~s}^{-1}\right.$; contours with $\left.\mathrm{ci}=0.3 \times 10^{6} \mathrm{~m}^{2} \mathrm{~s}^{-1}\right)$, and rotational wind $\left(\mathrm{m} \mathrm{s}^{-1}\right.$; vectors $)$ at $850 \mathrm{hPa}$ anomalies in (top) JFM, (middle) FMA, and (bottom) MAM onto the DJF Niño-3.4 index. Statistically significant areas at $95 \%$ confidence level are gridded for shading and vectors, and shaded/bolded for contours [(left) and (right), respectively].

Fs $\sim 10 \mathrm{Wm}^{-2}$ (Fig. 7), the spring warming would be $\sim 0.16 \mathrm{~K}$ month $^{-1}$. Considering an anomalous reduction of about $10 \%$ in the MLD (Fig. 5e), the spring warming would reach $\sim 0.18 \mathrm{Kmonth}^{-1}$, which is consistent with previous works (e.g., Chiang et al. 2002) but overestimates the observed SST anomaly in the season (Fig. 3e). The interpretation of this overestimation is that ocean heat transport is acting to damp the SST anomalies (Chang et al. 2001, 2002).

It has been previously reported that the most significant ENSO influence on the TNA is over the central part of the basin (e.g., Huang et al. 2002), while crossequatorial winds indirectly develop in tandem with the anomalous meridional SST gradient over the eastern part (Fig. 3e; Chiang et al. 2002). Note that no significant turbulent heat flux anomalies (Fig. 4f) or MLD changes (Fig. 5d) are found over the eastern TNA, off the African coast. The positive feedback there seems to operate as follows: a cross-equatorial SST gradient leads to a meridional pressure gradient through differential heating of the boundary layer, and this pressure gradient drives cross-equatorial winds (Chiang et al. 2002). The results shown here suggest that the ENSO impact on the central TNA could be explained by the weakening of the trade winds associated with the secondary Gill-type response in spring, with no required link to winter conditions. The question that remains is why the ENSOrelated SST anomalies in MAM are larger than in DJF (Figs. 2b, 3e, and S4). Figure 6c shows an overall seasonal increase of interannual SST variance in the TNA region (similarly for HadISST; Fig. S5), which could simply explain the distinct amplitudes, since the anomaly tends to be stronger where the variability is higher. An attempt has finally been made to examine this interseasonal increase in SST variance. A possibility may be that TNA SST is more sensitive in MAM. 
Niño3.4 (djf) x MLD (djf)

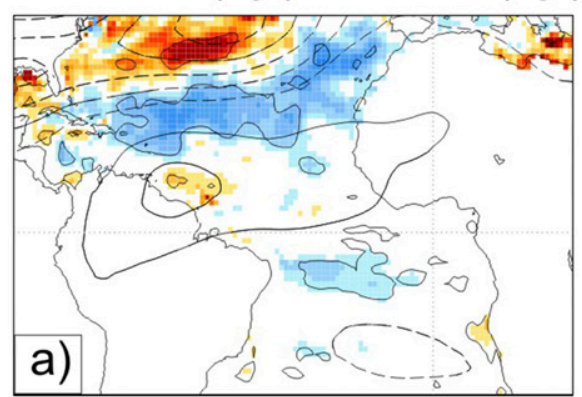

\section{Niño3.4 (djf) x MLD (fma)}

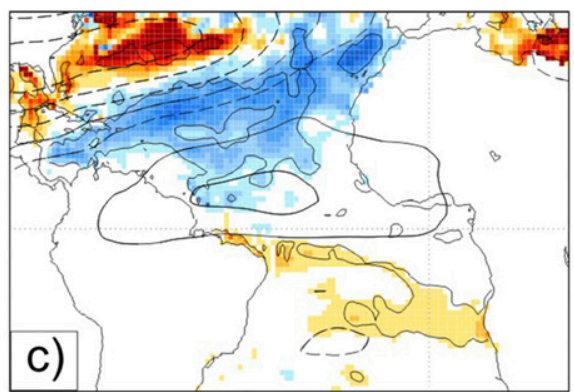

Niño3.4 (djf) x MLD (jfm)

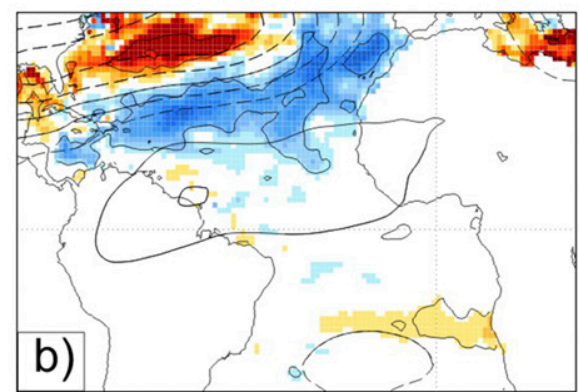

Niño3.4 (djf) x MLD (mam)

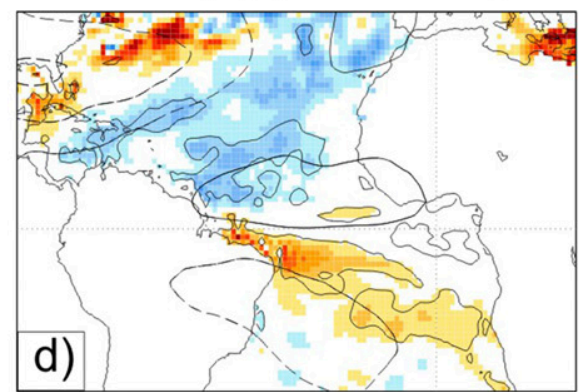

$-8-7-6-5-4-3-2-1$
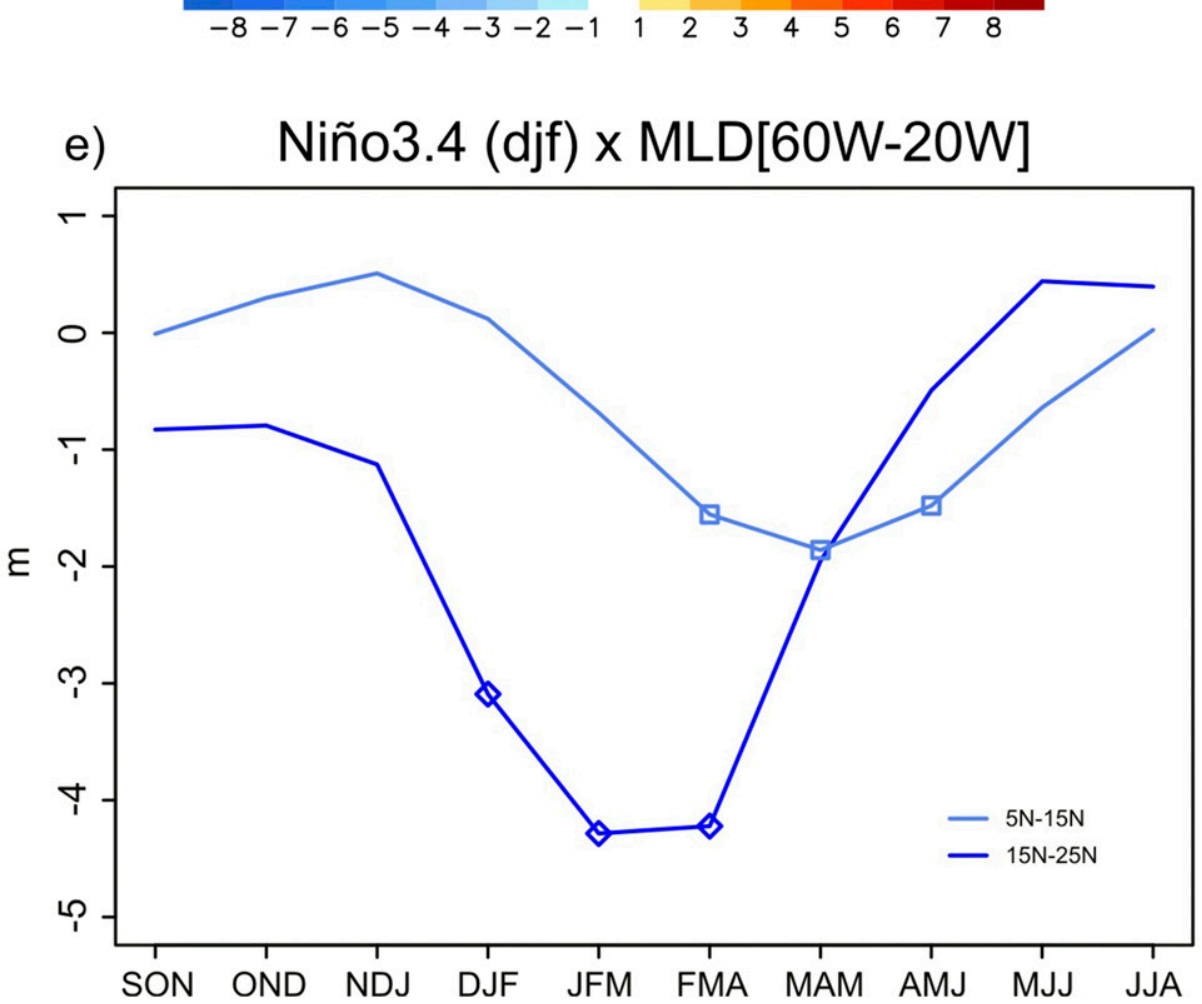

FIG. 5. Regression map of MLD (m; shading) anomalies in (a) DJF, (b) JFM, (c) FMA, and (d) MAM onto the DJF Niño-3.4 index. Statistically significant areas at 95\% confidence level are contoured. In each panel the regression of streamfunction anomalies at $850 \mathrm{hPa}\left(\mathrm{m}^{2} \mathrm{~s}^{-1}\right.$; contours with ci $\left.=0.3 \times 10^{6} \mathrm{~m}^{2} \mathrm{~s}^{-1}\right)$ is plotted, as in Figs. 2e and 4 (right). (e) Regression of MLD anomalies zonally averaged over the TNA domain $60^{\circ}-20^{\circ} \mathrm{W}$ (Czaja et al. 2002) in the $5^{\circ}-15^{\circ} \mathrm{N}$ (light blue) and $15^{\circ}-25^{\circ} \mathrm{N}$ (dark blue) latitudinal bands. Symbols indicate statistically significant anomalies at $95 \%$ confidence level. 
stdev SST (djf)

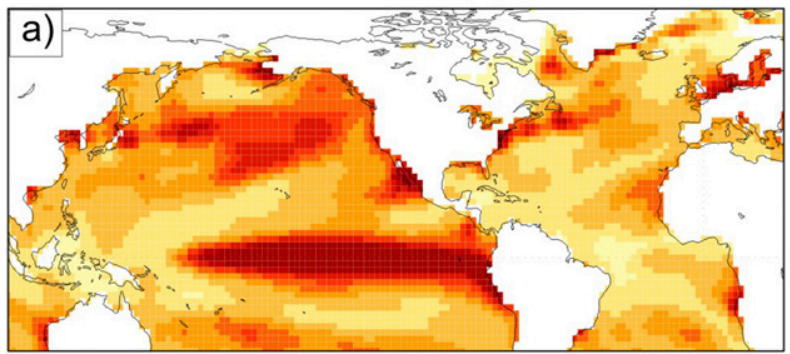

stdev SST (mam)

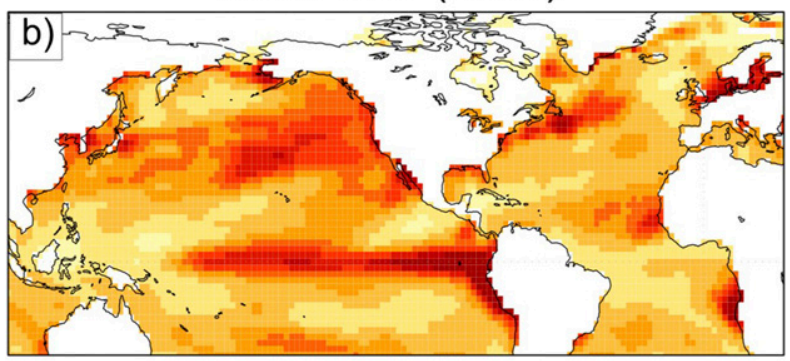

$\begin{array}{lllllllll}0.1 & 0.2 & 0.3 & 0.4 & 0.5 & 0.6 & 0.7 & 0.8 & 0.9\end{array}$

\section{stdev SST / clim MLD (mam-djf)}

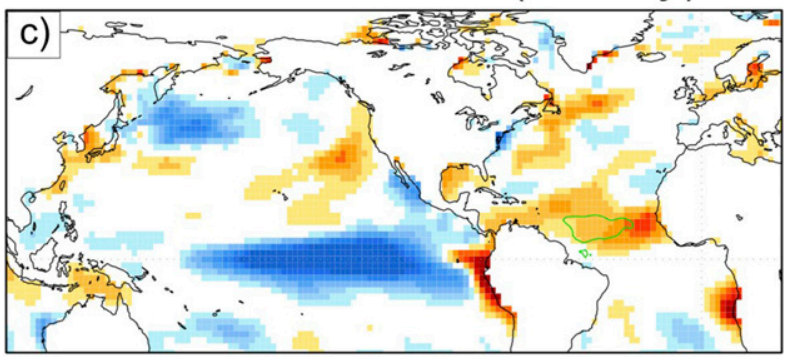

$\begin{array}{llll}-0.4 & -0.3 & -0.2 & -0.1\end{array}$

$\begin{array}{llll}0.1 & 0.2 & 0.3 & 0.4\end{array}$

FIG. 6. Std dev of SST ( ${ }^{\circ} \mathrm{C}$; shading) in (a) DJF and (b) MAM, and (c) its difference, over the period 1982/83-2010/11. Areas in the TNA region where the MLD is deeper in MAM as compared to DJF are contoured in (c).

Seasonal changes in MLD, specific humidity, latent heat flux, and shortwave radiation appear as potential agents for this (Fig. 8 and Figs. S6-S9), probably linked to seasonal changes of the Atlantic ITCZ (Chiang et al. 2002). A set of suitable ocean-only simulations would be required to address this issue. An alternative may be that TNA SST variability in MAM is higher because the ENSO forcing in this season is stronger. Figure 9 shows the monthly autocorrelation of the TNA SST index $\left(5^{\circ}-25^{\circ} \mathrm{N}, 60^{\circ}-20^{\circ} \mathrm{W}\right.$; Czaja et al. 2002). TNA SST yields the annual maxima in month-to-month correlation for March > April and April > May; thereby, MAM holds maximum monthly autocorrelation in the annual cycle.
This reveals a decrease of intraseasonal variability but at the same time an increase of interannual variability, which could explain the interseasonal increase in SST variance from DJF to MAM. It also implies that there is a persistent forcing of TNA SST, which may well be ENSO (e.g., Enfield and Mayer 1997; Sutton et al. 2000). The working hypothesis here goes along with this result. Targeted coupled simulations would facilitate obtaining a robust conclusion.

\section{Summary and discussion}

This observational study presents and describes a fourth potential mechanism to explain the ENSO teleconnection to the tropical North Atlantic in boreal spring. The continuous ENSO-induced atmospheric forcing in the tropical Atlantic via the remote Gill-type response plus the climatological springtime increase in SST variance over the TNA region may conceivably be underlying the one-season-lagged ENSO-TNA teleconnection. This mechanism would be at work for long-lasting ENSO events because of the in-phase Gill-type response, while no significant TNA SST anomalies are expected in case of shorter-lived ones according to this mechanism and in line with Lee et al. (2008). Preconditioning of the tropical Atlantic could also play a major role (e.g., Giannini et al. 2004; Barreiro et al. 2005).

The teleconnection mechanism proposed here (Fig. 1, right) does not come into conflict with the three other mechanisms proposed until now (Fig. 1, left), but helps to address some unclear issues concerning the ENSOTNA relationship for which they do not provide a satisfactory insight. In particular, the remote Gill-type response in the tropical Atlantic can provide the atmospheric forcing needed at low latitudes of the TNA during the ENSO decaying phase to trigger the air-sea coupling there at the right timing. As discussed by Czaja et al. (2002), once the subtropical wind anomalies vanish toward spring, the air-sea interaction and SST anomalies remain only in the deep TNA; any ENSO-related signal north of $10^{\circ} / 15^{\circ} \mathrm{N}$ tends to damp. In accordance with Lee et al. (2008) and partially in disagreement with Czaja et al. (2002), the remote Gill-type mechanism constitutes a regional atmospheric forcing rather than the expression of the WES feedback. The dynamics of the secondary Gill-type response to ENSO in the tropical Atlantic during spring have been recently simulated in a coupled GCM (Sasaki et al. 2015), although the focus was the impact on equatorial precipitation, not on TNA SSTs. The results shown here on the transition from a subtropical forcing associated with the extratropical ENSO teleconnection (in winter/late winter; via Rossby wave train and/or Walker-Hadley) into a 

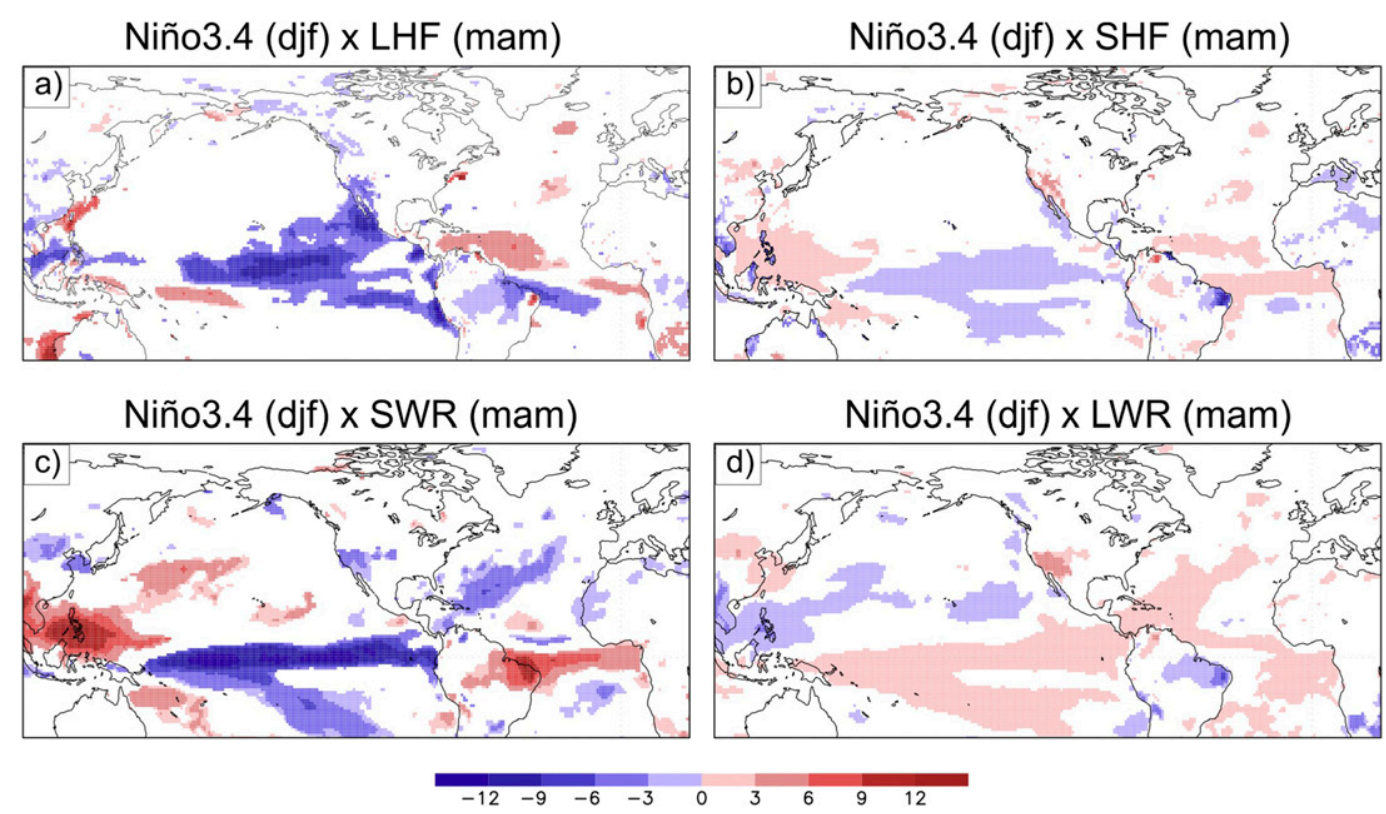

FIG. 7. Regression map of surface (a) latent heat flux (LHF), (b) sensible heat flux (SHF), (c) shortwave radiation (SWR), and (d) longwave radiation (LWR) anomalies in MAM onto the DJF Niño-3.4 index; downward is positive $\left(\mathrm{W} \mathrm{m}^{-2}\right)$. Statistically significant areas at $95 \%$ confidence level are gridded.

tropical forcing associated with the remote Gill-type response (in early spring/spring) are consistent with previous studies reporting a similar winter-to-spring evolution in observations (e.g., Chiang et al. 2002) and atmosphere-only (e.g., Sutton et al. 2000) and coupled (e.g., Huang et al. 2002) GCM simulations. Dedicated sensitivity experiments, such as the pacemaker experiments by Douville et al. (2015) prescribing only observed SST variability in the tropical Pacific, are required to provide modeling support to the role of the secondary Gill-type response in the ENSO-TNA teleconnection and to assess the associated predictability.
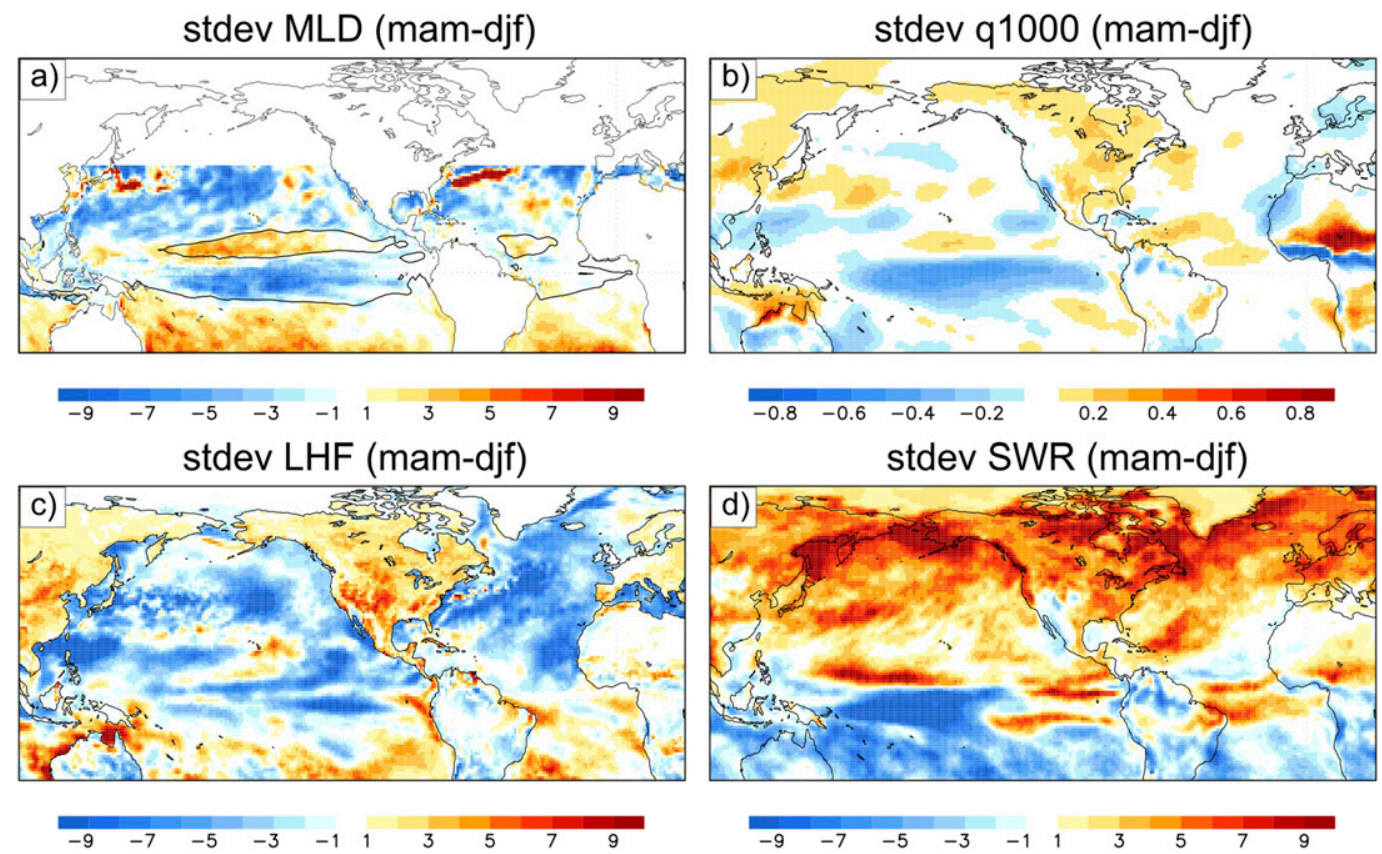

FIG. 8. As Fig. 6c, but for (a) MLD (m), (b) specific humidity at $1000 \mathrm{hPa} q_{1000}\left(\mathrm{~g} \mathrm{~kg}^{-1}\right)$, (c) surface LHF (W m $\left.{ }^{-2}\right)$, and (d) SWR $\left(\mathrm{W} \mathrm{m}^{-2}\right)$. Regions where MLD is deeper in MAM as compared to DJF are contoured in (a). 


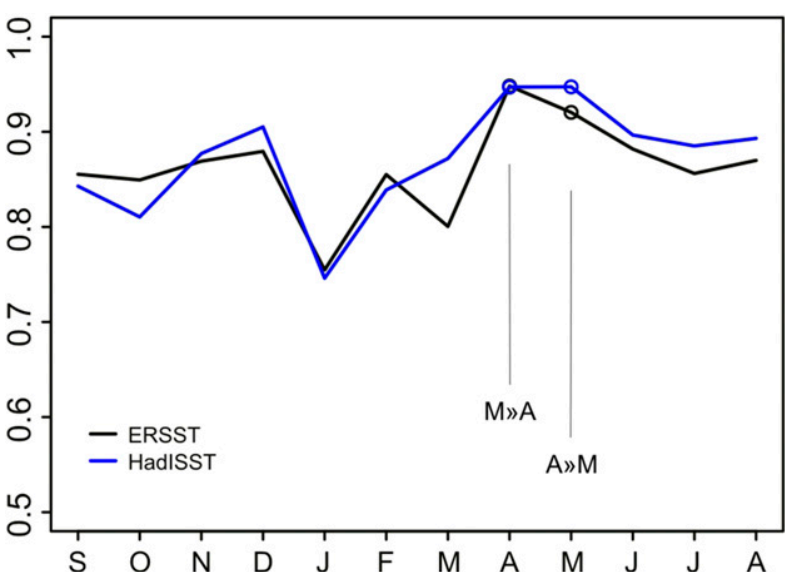

FIG. 9. Lagged correlation of SST anomalies averaged over the TNA $\left(5^{\circ}-15^{\circ} \mathrm{N}, 60^{\circ}-20^{\circ} \mathrm{W}\right.$; Czaja et al. 2002$)$ between the target month indicated in the $x$ axis and the previous month, computed over the period 1982/83-2010/11, from ERSST.v3b (black) and HadISST.v1.1 (blue). The two highest correlations in the annual cycle are indicated by open circles, which correspond to March $>$ April and April > May.

The proposed mechanism hints at some unresolved elements of the ENSO teleconnection to the tropical Atlantic, such as the twin minima in tropospheric air temperature (Yulaeva and Wallace 1994; see Fig. S10), lower-level anticyclonic anomalies over the TNA (Sutton et al. 2000), and the anomalous easterly winds in the equatorial Atlantic (Chang et al. 2006). The remote Gill-type response and the associated Rossby wave source may also provide a dynamical framework to understand other extratropical ENSO teleconnections (see Fig. S11), such as the secondary Rossby wave train suggested by Toniazzo and Scaife (2006) for mid-/late winter, or the ENSO influence on Europe in spring (van Oldenborgh et al. 2000; Mariotti et al. 2002).

Acknowledgments. This work has been supported by the EU/H2020-funded MSCA-IF-EF DPETNA project (GA 655339) and JG-S was partially supported by the Spanish MINECO-funded DANAE Project (CGL201568342-R). Technical support at BSC (Computational Earth Sciences group) is sincerely acknowledged. The authors are grateful to the anonymous reviewers for their comments, which helped to improve the scope of the manuscript.

\section{REFERENCES}

Adler, R. F., and Coauthors, 2003: The version-2 Global Precipitation Climatology Project (GPCP) Monthly Precipitation Analysis (1979-present). J. Hydrometeor., 4, 1147-1167, doi:10.1175/1525-7541(2003)004<1147:TVGPCP>2.0.CO;2.
Alexander, M. A., and J. Scott, 2002: The influence of ENSO on air-sea interaction in the Atlantic. Geophys. Res. Lett., 29, 1701, doi:10.1029/2001GL014347.

_ - I. Bladé, M. Newman, J. R. Lanzante, N.-C. Lau, and J. D. Scott, 2002: The atmospheric bridge: The influence of ENSO teleconnections on air-sea interaction over the global oceans. J. Climate, 15, 2205-2231, doi:10.1175/1520-0442(2002)015<2205: TABTIO $>2.0 . C O ; 2$.

Balmaseda, M. A., K. Mogensen, and A. T. Weaver, 2013: Evaluation of the ECMWF ocean reanalysis ORAS4. Quart. J. Roy. Meteor. Soc., 139, 1132-1161, doi:10.1002/qj.2063.

Barreiro, M., P. Chang, L. Ji, R. Saravanan, and A. Giannini, 2005: Dynamical elements of predicting boreal spring tropical Atlantic sea-surface temperatures. Dyn. Atmos. Oceans, 39, 6185, doi:10.1016/j.dynatmoce.2004.10.013.

Capotondi, A., and Coauthors, 2015: Understanding ENSO diversity. Bull. Amer. Meteor. Soc., 96, 921-938, doi:10.1175/ BAMS-D-13-00117.1.

Chang, P., L. Ji, and R. Saravanan, 2001: A hybrid coupled model study of tropical Atlantic variability. J. Climate, 14, 361-390, doi:10.1175/1520-0442(2001)013<0361:AHCMSO > 2.0.CO;2.

— , Y. Fang, R. Saravanan, L. Ji, and H. Seidel, 2006: The cause of the fragile relationship between the Pacific El Niño and the Atlantic Niño. Nature, 443, 324-328, doi:10.1038/nature05053.

Chiang, J. C. H., and A. H. Sobel, 2002: Tropical tropospheric temperature variations caused by ENSO and their influence on the remote tropical climate. J. Climate, 15, 2616-2631, doi:10.1175/1520-0442(2002)015<2616:TTTVCB >2.0.CO;2.

— , and B. R. Lintner, 2005: Mechanisms of remote tropical surface warming during El Niño. J. Climate, 18, 4130-4149, doi:10.1175/JCLI3529.1.

_, Y. Kushnir, and A. Giannini, 2002: Deconstructing Atlantic intertropical convergence zone variability: Influence of the local cross-equatorial sea surface temperature gradient and remote forcing from the eastern equatorial Pacific. J. Geophys. Res., 107, doi:10.1029/2000JD000307.

Czaja, A., P. van der Vaart, and J. Marshall, 2002: A diagnostic study of the role of remote forcing in tropical Atlantic variability. J. Climate, 15, 3280-3290, doi:10.1175/ 1520-0442(2002)015<3280:ADSOTR>2.0.CO;2.

Dee, D. P., and Coauthors, 2011: The ERA-Interim reanalysis: Configuration and performance of the data assimilation system. Quart. J. Roy. Meteor. Soc., 137, 553-597, doi:10.1002/ qj. 828 .

Deser, C., M. A. Alexander, S.-P. Xie, and A. S. Phillips, 2010: Sea surface temperature variability: Patterns and mechanisms. Annu. Rev. Mar. Sci., 2, 115-143, doi:10.1146/ annurev-marine-120408-151453.

DeWeaver, E., and S. Nigam, 2002: Linearity in ENSO's atmospheric response. J. Climate, 15, 2446-2461, doi:10.1175/ 1520-0442(2002)015<2446:LIESAR > 2.0.CO;2.

, and — 2004: On the forcing of ENSO teleconnections by anomalous heating and cooling. J. Climate, 17, 3225-3235, doi:10.1175/1520-0442(2004)017<3225:OTFOET>2.0.CO;2.

Douville, H., A. Voldoire, and O. Geoffroy, 2015: The recent global warming hiatus: What is the role of Pacific variability? Geophys. Res. Lett., 42, 880-888, doi:10.1002/2014GL062775.

Enfield, D. B., and D. A. Mayer, 1997: Tropical Atlantic sea surface temperature variability and its relation to El Niño-Southern Oscillation. J. Geophys. Res., 102, 929-945, doi:10.1029/ 96JC03296.

Giannini, A., Y. Kushnir, and M. A. Cane, 2000: Interannual variability of Caribbean rainfall, ENSO, and the Atlantic Ocean. 
J. Climate, 13, 297-311, doi:10.1175/1520-0442(2000)013<0297: IVOCRE $>2.0 . \mathrm{CO} ; 2$.

- J. C. H. Chiang, M. A. Cane, Y. Kushnir, and R. Seager, 2001: The ENSO teleconnection to the tropical Atlantic Ocean: Contributions of the remote and local SSTs to rainfall variability in the tropical Americas. J. Climate, 14, 4530-4544, doi:10.1175/1520-0442(2001)014<4530: TETTTT $>2.0 . \mathrm{CO} ; 2$.

— R. Raravanan, and P. Chang, 2004: The preconditioning role of tropical Atlantic variability in the development of the ENSO teleconnection: Implications for the prediction of Nordeste rainfall. Climate Dyn., 22, 839-855, doi:10.1007/ s00382-004-0420-2.

Gill, A. E., 1980: Some simple solutions for heat-induced tropical circulation. Quart. J. Roy. Meteor. Soc., 106, 447-462, doi:10.1002/qj.49710644905.

Handoh, I. C., A. J. Matthews, G. R. Bigg, and D. P. Stevens, 2006: Interannual variability of the tropical Atlantic independent of and associated with ENSO: Part I. The north tropical Atlantic. Int. J. Climatol., 26, 1937-1956, doi:10.1002/ joc. 1343 .

Hoskins, B. J., and D. Karoly, 1981: The steady linear response of a spherical atmosphere to thermal and orographic forcing. J. Atmos. Sci., 38, 1179-1196, doi:10.1175/1520-0469(1981)038<1179: TSLROA $>2.0 . \mathrm{CO} ; 2$.

Huang, B., P. S. Schopf, and Z. Pan, 2002: The ENSO effect on the tropical Atlantic variability: A regionally coupled model study. Geophys. Res. Lett., 29, 2039, doi:10.1029/ 2002 GL014872.

Jang, Y., and D. M. Straus, 2013: Tropical stationary wave response to ENSO: Diabatic heating influence on the Indian summer monsoon. J. Atmos. Sci., 70, 193-222, doi:10.1175/ JAS-D-12-036.1.

Kalnay, E., and Coauthors, 1996: The NCEP/NCAR 40-Year Reanalysis Project. Bull. Amer. Meteor. Soc., 77, 437-471, doi:10.1175/1520-0477(1996)077<0437:TNYRP>2.0.CO;2.

Kirtman, B. P., and Coauthors, 2014: The North American Multimodel Ensemble: Phase-1 seasonal-to-interannual prediction; Phase-2 toward developing intraseasonal prediction. Bull. Amer. Meteor. Soc., 95, 585-601, doi:10.1175/ BAMS-D-12-00050.1.

Klein, S. A., B. J. Soden, and N.-C. Lau, 1999: Remote sea surface temperature variations during ENSO: Evidence for a tropical atmospheric bridge. J. Climate, 12, 917-932, doi:10.1175/ 1520-0442(1999)012<0917:RSSTVD>2.0.CO;2.

Kucharski, F., A. Bracco, J. H. Yoo, and F. Molteni, 2007: Lowfrequency variability of the Indian monsoon-ENSO relationship and the tropical Atlantic: The "weakening" of the 1980s and 1990s. J. Climate, 20, 4255-4266, doi:10.1175/ JCLI4254.1.

,,--- , and 2008: Atlantic forced component of the Indian monsoon interannual variability. Geophys. Res. Lett., 35, L04706, doi:10.1029/2007GL033037.

, - - A. M. Tompkins, L. Feudale, P. Ruti, and A. Dell'Aquila, 2009: A Gill-Matsuno-type mechanism explains the tropical Atlantic influence on African and Indian monsoon rainfall. Quart. J. Roy. Meteor. Soc., 135, 569-579, doi:10.1002/qj.406.

Lau, K.-M., and P. H. Chan, 1983: Short-term climate variability and atmospheric teleconnections from satellite-observed outgoing longwave radiation. Part I: Simultaneous relationships. J. Atmos. Sci., 40, 2735-2750, doi:10.1175/1520-0469(1983)040<2735: STCVAA $>2.0 . \mathrm{CO} ; 2$.
Lee, S.-K., D. B. Enfield, and C. Wang, 2008: Why do some El Niños have no impact on tropical North Atlantic SST? Geophys. Res. Lett., 35, L16705, doi:10.1029/2008GL034734.

— C. Wang, and B. E. Mapes, 2009: A simple atmospheric model of the local and teleconnection responses to tropical heating anomalies. J. Climate, 22, 272-284, doi:10.1175/ 2008JCLI2303.1.

Lin, H., J. Derome, and G. Brunet, 2007: A hybrid coupled model study of tropical Atlantic variability. J. Climate, 20, 5642-5665, doi:10.1175/2007JCLI1383.1.

Lintner, B. R., and J. C. H. Chiang, 2007: Adjustment of the remote tropical climate to El Niño conditions. J. Climate, 20, 2544 2557, doi:10.1175/JCLI4138.1.

Mariotti, A., N. Zeng, and K.-M. Lau, 2002: Euro-Mediterranean rainfall and ENSO-A seasonally varying relationship. Geophys. Res. Lett., 29, doi:10.1029/2001GL014248.

Matsuno, T., 1966: Quasi-geostrophic motions in the equatorial area. J. Meteor. Soc. Japan, 44, 25-43, doi:10.2151/jmsj1965.44.1_25.

Nigam, S., C. Chung, and E. DeWeaver, 2000: ENSO diabatic heating in ECMWF and NCEP-NCAR reanalyses, and NCAR CCM3 simulation. J. Climate, 13, 3152-3171, doi:10.1175/1520-0442(2000)013<3152:EDHIEA > 2.0.CO;2.

Rayner, N. A., D. E. Parker, E. B. Horton, C. K. Folland, L. V. Alexander, D. P. Rowell, E. C. Kent, and A. Kaplan, 2003: Global analyses of sea surface temperature, sea ice, and night marine air temperature since the late nineteenth century. J. Geophys. Res., 108, 4407, doi:10.1029/2002JD002670.

Saravanan, R., and P. Chang, 2000: Interaction between tropical Atlantic variability and El Niño-Southern Oscillation. J. Climate, 13, 2177-2194, doi:10.1175/1520-0442(2000)013<2177: IBTAVA $>2.0 . \mathrm{CO} ; 2$.

Sardeshmukh, P. D., and B. J. Hoskins, 1988: The generation of global rotational flow by steady idealized tropical divergence. J. Atmos. Sci., 45, 1228-1251, doi:10.1175/ 1520-0469(1988)045<1228:TGOGRF > 2.0.CO;2.

Sasaki, W., T. Doi, K. J. Richards, and Y. Masumoto, 2015: The influence of ENSO on the equatorial Atlantic precipitation through the Walker circulation in a CGCM. Climate Dyn., 44, 191-202, doi:10.1007/s00382-014-2133-5.

Smith, T. M., R. W. Reynolds, T. C. Peterson, and L. Lawrimore, 2008: Improvements to NOAA's historical merged landocean surface temperature analysis (1880-2006). J. Climate, 21, 2283-2296, doi:10.1175/2007JCLI2100.1.

Spencer, H., J. M. Slingo, and M. K. Davey, 2004: Seasonal predictability of ENSO teleconnections: The role of the remote ocean response. Climate Dyn., 22, 511-526, doi:10.1007/ s00382-004-0393-1.

Sterl, A., G. J. van Oldenborgh, W. Hazeleger, and G. Burgers, 2007: On the robustness of ENSO teleconnections. Climate Dyn., 29, 469-485, doi:10.1007/s00382-007-0251-z.

Stockdale, T. N., F. Molteni, and L. Ferranti, 2015: Atmospheric initial conditions and the predictability of the Arctic Oscillation. Geophys. Res. Lett., 42, 1173-1179, doi:10.1002/ 2014GL062681.

Sutton, R. T., S. P. Jewson, and D. P. Rowell, 2000: The elements of climate variability in the tropical Atlantic region. J. Climate, 13, 3261-3284, doi:10.1175/1520-0442(2000)013<3261: TEOCVI>2.0.CO;2.

Toniazzo, T., and A. A. Scaife, 2006: The influence of ENSO on winter North Atlantic climate. Geophys. Res. Lett., 33 L24704, doi:10.1029/2006GL027881.

Trenberth, K. E., G. Branstator, D. Karoly, A. Kumar, N.-C. Lau, and C. Ropelewski, 1998: Progress during TOGA in understanding 
and modeling global teleconnections associated with tropical sea surface temperatures. J. Geophys. Res., 103, 14291-14324, doi:10.1029/97JC01444.

van Oldenborgh, G. J., G. Burgers, and A. K. Tank, 2000: On the El Niño teleconnection to spring precipitation in Europe. Int. J. Climatol., 20, 565-574, doi:10.1002/ (SICI)1097-0088(200004)20:5<565::AID-JOC488>3.0.CO;2-5.

Wang, C., 2005: ENSO, Atlantic climate variability and the Walker and Hadley circulations. The Hadley Circulation: Present, Past and Future, H. F. Diaz and R. S. Bradley, Eds., Cambridge University Press, 173-202.

Yang, X., and T. DelSole, 2012: Systematic comparison of ENSO teleconnection patterns between models and observations. J. Climate, 25, 425-446, doi:10.1175/JCLI-D-11-00175.1.

Yulaeva, E., and J. M. Wallace, 1994: The signature of ENSO in global temperature and precipitation fields derived from the Microwave Sounding Unit. J. Climate, 7, 1719-1736, doi:10.1175/ 1520-0442(1994)007<1719:TSOEIG>2.0.CO;2. 